\title{
ANÁLISE COMPARATIVA DOS MOTIVOS DE RETIRADA NÃO ELETIVA DO CATETER CENTRAL DE INSERÇÃO PERIFÉRICA NA UNIDADE NEONATAL DO HOSPITAL MUNICIPAL DR. JOSÉ DE CARVALHO FLORENCE (HMJCF) \\ Avaliação e Qualidade do Cuidado
}

Maria Aparecida Vieira Diniz Lopes; Meire Marques Guimarães; Karen Mendes Borges; Maria Cristina Pose Guerra; Renata Mantovani

\section{INTRODUÇÃO}

Atualmente o Cateter Central de Inserção Periférica (PICC) é o dispositivo mais utilizado nas Unidades de Neonatologia (UTINN) devido a gama de benefícios se comparado a outros cateteres', 0 enfermeiro capacitado, amparado na Resolução Cofen-258/2001 pode realizar a passagem do cateter ${ }^{2}$.

\section{OBJETIVO}

Realizar uma análise comparativa dos motivos de retirada não eletiva do PICC na UTINN do HMJCF.

\section{METODOLOGIA}

Estudo descritivo, documental, com abordagem quantitativa. Realizado por levantamento do banco de dados referente ao número de PICCs inseridos no período de JAN/SET de 2017-2018.

\section{RESULTADO}

Contabilizamos 190 cateteres inseridos em 2017 e em 2018195 cateteres, destes: Tivemos aumento no número de perdas por óbito, sinais de infecção corroborando com a maioria dos estudos realizados sobre o assunto e infiltração, ressaltando que em 100\% das infiltrações os cateteres estavam periféricos

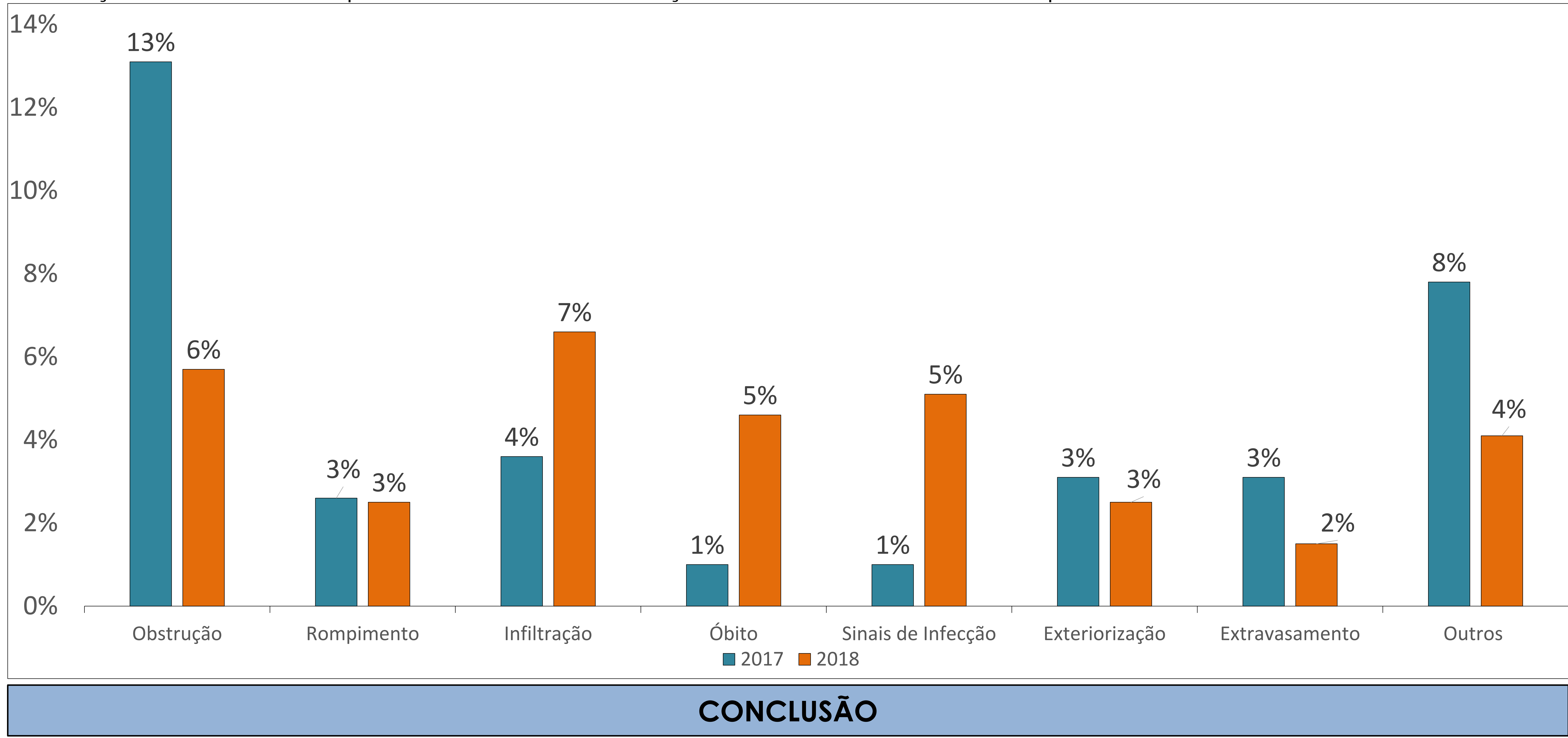

Os dados mostram melhora das taxas na maioria dos itens no ano de 2018 em relação a 2017, tivemos uma diminuição significativa de retirada por motivos evitáveis como: obstrução, rompimento, exteriorização, extravasamento e outros. Atribuímos o resultado a qualificação da equipe de enfermagem e aquisição do PICC 2.0 Fr pela instituição. Os motivos de remoção não eletivas indicaram necessidade de estratégias para prevenção de complicações evitáveis relacionadas ao PICC.

\section{REFERÊNCIAS:}

TINISHA M. et al. First Golden Hour of Life. Advance in Neonatal Care. Vol.16, No. 4, pp.264-272. Copiright 2016 National Association of Neonatal Nurses Unautothorized rencoduction of this article is prohibited. 